\title{
Quando vivências humanas constroem Oásis: reflexões a partir da pedagogia de Freire sobre a atuação do pedagogo na educação não formal
}

\author{
When human experiences build oases: reflexions from the pedagogy of Paulo \\ Freire about the role of the pedagogue in non-formal education
}

\author{
Carla da Silva de Jesus ${ }^{1}$ \\ Alice Costa Macedo 2 \\ Jaqueline Braga Morais Cajaiba ${ }^{3}$
}

\section{Resumo}

O presente artigo, amparado na teoria freiriana, discute o papel do pedagogo em espaços de educação não formal, observando a prática pedagógica e as possibilidades de atuação desse profissional em ambientes não escolares. Constituiu-se em uma pesquisa qualitativa com base na observação participante, entrevista semiestruturada e notas em diário de campo. A pesquisa foi realizada em uma instituição não governamental, a Associação Beneficente Oásis, da cidade de Amargosa, no Recôncavo da Bahia. Abordouse, como discussão dos resultados, a sistematização de métodos pedagógicos da educação não formal e a função do pedagogo nessa modalidade educativa com crianças, adolescentes e mulheres que se encontram com demandas de quem vive no local com poucos recursos financeiros e em um contexto que apresenta grandes desafios. Percebeu-se que o educador nesse cenário deve apresentar, em seu ofício, flexibilidade e fluidez, com a proposta de formar sujeitos críticos a partir da educação popular e libertadora voltada à autonomia do sujeito, à luta pela justiça e capaz de transformar mundos.

Palavras-chave: Educação não formal. Pedagogia da autonomia. Educação não escolar.

\begin{abstract}
This article, supported by Freirean theory, discusses the role of the pedagogue in spaces of non-formal education, observing the pedagogic practice and the possibilities of performance for this kind of professional in non-school environments. It was conducted in a qualitative research based on participant observation, semi-structured interviews and notes on a field journal. The research was carried out in a non-governmental institution,

\footnotetext{
${ }^{1}$ Graduada em Pedagogia pela Universidade Federal da Bahia ( UFRB), Centro de Formação de Professores ( (FP), Amargosa- BA. E-mail: karllazgvl@hotmail.com

${ }^{2}$ Doutora em psicologia pela Universidade de São Paulo (USP), professora adjunta do Centro de Formação de Professores da Universidade Federal do Recôncavo da Bahia (CFP-UFRB). Email: alicemacedo@ufrb.edu.br

3 Bacharela em Psicologia(FTC), Especialista em Psicologia da Educação(FJT) e em Gestão em Saúde Pública(UESC). Graduanda em Letras Vernáculas (UESC). Integrante do Grupo de Estudos e Pesquisas em Movimentos Sociais e Educação do Campo e da Cidade - GEPEMDECC- UESB. Email: jaqueline.braga.psi@gmail.com
} 


\section{-Revista de Iniciação à Docência, v.6, n.2, 2021- \\ Publicação: dezembro, 2021 - ISSN 2525-4332}

called "Associação Beneficente Oásis," in the city of Amargosa - Bahia - Brazil. As a discussion of the results, the systematization of pedagogic methods of non-formal education and the role of the pedagogue in this educational modality with kids, adolescents and women who meet demands of living locally with few financial resources and in a context that presents great challenges was addressed. It was noticed that the educator in this scenario must present, in their craft, flexibility and fluidity, with the purpose of forming critical subjects starting from the liberating and popular education focused on the autonomy of the subject, the fight for justice and the capability of changing worlds.

Keywords: Non-formal education. Pedagogy of autonomy. Non-school education.

\section{Introdução}

A prática do pedagogo é comumente (ou quase sempre) associada aos espaços de educação formal, sobretudo as escolas. Ao partir desse contexto, ampara-se na teoria freiriana para discutir o papel do pedagogo em espaços de educação não formal, ao observar sua atuação em ambientes diversos, a partir de um estudo de caso em uma Associação na cidade de Amargosa, no Recôncavo da Bahia. A escolha desse tema visa contribuir para fomentar maior interesse e discussão sobre as práticas pedagógicas, despertando para a multiplicidade de perspectivas em diferentes campos de trabalho, inclusive em espaços não escolares, que sejam públicos, privados ou comunitários.

\footnotetext{
Ninguém escapa da educação. Em casa, na rua, na igreja, na escola, de um modo ou de muitos, todos nós envolvemos pedaços da vida com ela: Para aprender, para ensinar, para aprender-e-ensinar, para saber, para fazer, para ser ou para conviver, todos os dias misturamos a vida com educação. [...] não há uma forma única, nem um único modelo de educação; a escola não é o único lugar em que ela acontece e talvez nem seja o melhor; o ensino escolar não é a única prática (BRANDÃO, 2007, p. 7).
}

Brandão (2007) explicita que onde existe humanidade, acontece a educação, mesmo sem haver o ensino especializado e formal. Conforme corrobora Libâneo (1998), o que justifica a existência da pedagogia é o fato de esse campo ocupar-se do estudo sistemático das práticas educativas que se realizam em sociedade, como processos fundamentais da condição humana. A pedagogia, segundo o autor, serve para investigar a natureza, as finalidades e os processos necessários às práticas educativas, com o objetivo de propor a realização desses processos em diversos contextos.

Assim é possível refletir que a educação não formal se constitui enquanto modalidade de prática educativa, sendo, portanto, um processo que ultrapassa as barreiras da escola e apresenta uma metodologia própria, construída coletivamente. A variedade de métodos e estratégias inclui uma intencionalidade, tanto educativa quanto política e social, exigindo que o pedagogo sempre conheça as necessidades dos educandos atendidos ao atuar em sua prática. 
Gohn (2010) traz indagações importantes que contribuem para a atuação do educador social nessa prática da educação não formal, visto que é preciso exercer um papel ativo, propositivo e interativo com qualidade. É importante que existam metodologias de trabalho autônomas, para que haja o diálogo, sem desvalorizar a cultura local, do outro, do diferente. Nesse sentido, é imprescindível conhecer o público-alvo, a fim de que os temas em voga sejam familiares ao cotidiano dos grupos, tornando-os participativos nos processos sociais, políticos e econômicos.

Levando em consideração todo esse cenário, o pedagogo deverá ser um profissional que possui competências e habilidades para trabalhar em processos de coordenação, planejamento, execução e avaliação, por exemplo, em organizações não governamentais (ONG's), associações, projetos sociais, espaços de militância etc. A atuação pedagógica nesses lugares contribui para a formação cidadã dos sujeitos, revelando ser necessário planejar a prática com base na análise do contexto social em que vivem e convivem os participantes. Espera-se que esta pesquisa possa contribuir para compreender a função do pedagogo na educação não formal, considerando desafios, potencialidades e perspectivas nesses espaços.

\section{A educação em debate: movimentos pendulares na formação do educador entre espaços formais e não formais}

A educação é um espaço privilegiado de desenvolvimento e formação humana, ao produzir conhecimentos que contribuem para o crescimento e a qualidade de vida das pessoas. Mesmo com o avanço nas últimas décadas, ainda há diversas lacunas educacionais que limitam essa transformação. Na década de 1970, Paulo Freire já discutia a potência da educação popular e libertadora, com e jamais para o povo: "é busca, desejo, esperança e luta de todos que, em comunhão, fazem sua história de libertação" (SCHNORR, 2010, p. 70).

Freire (1987) apresenta a humanização como "vocação dos homens", vocação veementemente negada na injustiça, na exploração, na opressão, na violência, mas passível de ser afirmada e defendida, sobretudo em contextos educacionais ávidos por liberdade, justiça e pela busca dessa "humanidade roubada". Tanto a formação de professores no Brasil quanto a sua atuação na educação exige essa reflexão crítica, pois, sem ela, a prática vai se esvaziando de sentido, vai se tornando engessada, escrava de uma lógica que oprime a si e o outro, não importa onde se situe o seu labor, seja em espaços formais, informais ou não formais.

De acordo com Gohn (2010, p.16), trata-se de três práticas distintas, que acontecem separadas e com autonomia:

[...] a educação formal como aquela desenvolvida nas escolas, com conteúdo previamente demarcados; a educação não formal é aquela que se aprende "no mundo da vida", via os processos de compartilhamento de experiências, 


\title{
-Revista de Iniciação à Docência, v.6, n.2, 2021- Publicação: dezembro, 2021 - ISSN 2525-4332
}

principalmente em espaços e ações coletivos cotidianos; e a educação informal como aquela na qual os indivíduos aprendem durante seu processo de socialização gerada nas relações e relacionamentos intra e extrafamiliares (amigos, escola, religião, clube, etc.). A informal incorpora valores e culturas próprias, de pertencimento e sentimentos herdados (GOHN, 2010, p. 16).

A educação formal é aquela que possui o enquadre das instituições educacionais de formação, a exemplo das escolas e da universidade:

\begin{abstract}
A educação aparece sempre que surgem formas sociais de condução e controle da aventura de ensinar-e-aprender. O ensino formal é o momento em que a educação se sujeita à pedagogia (a teoria da educação). Cria situações próprias para o seu exercício, produz os seus métodos, estabelece suas regras e tempos, e constitui executores especializados. É quando aparecem a escola, o aluno e o professor (BRANDÃO, 2007, p.26).
\end{abstract}

A educação formal segue diretrizes e padrões: exigem-se conteúdos préestabelecidos, avaliações padronizadas, métodos normatizados, currículos regularizados e exige-se uma formação específica para seus regentes. Nesse cenário, eis a questão que urge: e na educação não formal? Qual é a sua exigência e quais são os seus padrões?

A educação não formal ocorre fora dos espaços escolares, onde há a interação do indivíduo, tendo o propósito de praticar o ensino-aprendizagem em um local próprio, de forma não padronizada como na educação formal. Há intencionalidade na sua ação, ao atender determinados grupos de indivíduos que mostram interesse e tomam uma decisão de praticá-la voluntariamente (sem obrigatoriedade). Gohn (2010, p. 32) traz um conceito para educação não formal:

É um processo sociopolítico, cultural e pedagógico de formação para a cidadania, entendendo o político como a formação do indivíduo para interagir com o outro em sociedade. Ela designa um conjunto de práticas socioculturais de aprendizagem e produção de saberes, que envolve organizações/instituições, atividades, meios e formas variadas, assim como uma multiplicidade de programas e projetos sociais.

Nas ONG's, associações, espaços de militância, projetos sociais e movimentos populares, o pedagogo também pode atuar, mas sempre como mediador, a partir de sua formação e de seus materiais de apoio, para que o educando aprenda através das relações de todos os envolvidos de forma democrática. Para ser um educador nos espaços não escolares, não há necessariamente uma exigência acadêmica ou até mesmo de formação universitária específica. Porém, isso não significa que não haja outras modalidades de formação para que se tornem educadores sociais e mediadores. Os espaços de formação de cidadãos críticos possuem também seu rigor e sua ética, próprios de sua lógica e de seu contexto cultural.

A educação não formal é uma atividade também organizada e sistematizada, que está fora da referência do sistema formal, selecionando tipos de aprendizagem a subgrupos particulares da população, sejam estes adultos ou crianças, que desenvolvem habilidades e competências em que o desempenho dos indivíduos não é avaliado formalmente. Vale ressaltar a importância da formação dos profissionais da educação 
para atuar nesses espaços não formais, considerando-os mediadores de interesses que contribuem para a transformação social.

Segundo Freire (1996), educadores e educadoras se movem como tal porque primeiro se movem como gente, assim se constituem como profissionais idôneos e que têm uma postura e uma organização política. Portanto, devem carregar a convicção do princípio educativo enquanto uma forma de intervenção no mundo por se tratar de uma experiência exclusivamente humana (FREIRE, 1996). Logo, é preciso defender e lutar por um processo formativo e reflexivo dos educadores e educadoras de espaços não formais, afinal o envolvimento com a prática educativa refere-se à uma ação política, moral, gnosiológica, revolucionária que deve vislumbrar a transformação no mundo.

\section{A educação não formal no contexto brasileiro: uma perspectiva histórica}

Segundo Trilla (2008), o termo educação não formal apareceu no final da década de sessenta. Neste período surgiram discussões pedagógicas, diversos estudos sobre a crise na educação, as críticas radicais à instituição escolar, a formulação de novos conceitos e seus paradigmas. Assim, essa crise é sentida na escola e acaba por favorecer o surgimento do campo teórico da educação não formal.

A escola como instituição formal, intencional e com suas estruturas preparadas e pensadas para a humanidade, possuindo currículo definido, não consegue abranger todas as formas de aprendizagem do indivíduo. A formação do sujeito perpassa por outros espaços. Em contraponto, a prática não formal dá-se no relacionamento com o mundo, de modo que todas as estratégias, métodos e processos educativos são construídos com a comunidade.

Atualmente, a educação não formal vem ganhando importância, conquistando seu lugar em meio às políticas públicas. Desse modo, conforme afirma Gohn (1999, p. 91) "até os anos 80, a educação não-formal foi um campo de menor importância no Brasil, tanto nas políticas públicas quanto entre educadores. Todas as atenções estiveram centradas na educação formal”.

Nessa perspectiva, "a educação não-formal era vista como uma extensão da educação formal, que se desenvolvia em espaço externo a unidade escolar, de forma que propuseram ações com vistas ao fenômeno da leitura e escrita nesses espaços" (GOHN, 1999, p. 91). Sabe-se que o ensino-aprendizagem vai muito além do educando decodificar ou localizar informações nos textos. Por outro lado, com a situação do analfabetismo de adultos das camadas populares, na época, a educação não formal propiciava um espaço para que essas pessoas desenvolvessem a aprendizagem da leitura e da escrita, permitindo a participação ativa na sociedade política. É válido mencionar que, ainda segundo Gohn (1999, p.92): 


\section{-Revista de Iniciação à Docência, v.6, n.2, 2021- Publicação: dezembro, 2021 - ISSN 2525-4332}

O grande destaque que a educação não-formal passou a ter nos anos 90 decorre de mudanças na economia, na sociedade e no mundo do trabalho. Valorizando os processos de aprendizagem em grupos e a dar-se grande importância aos valores culturais que articulam as ações dos indivíduos.

Ao definir a educação não formal a autora enfatiza:

Que trabalha com um conceito amplo de educação associada a outro conceito, o de cultura. Isso significa que a educação é abordada enquanto forma de ensino/aprendizagem adquirida ao longo da vida dos cidadãos; pela leitura, interpretação e assimilação dos fatos, eventos e acontecimentos que os indivíduos fazem, de forma isoladas ou em contato com os grupos e organizações (GHON, 1999, p. 98).

Por fim, o pedagogo/educador precisa ter um olhar sensível às especificidades dos educandos, a fim de proporcionar condições de aprendizagem, seja nas organizações populares ou nos antigos ambientes alfabetizadores, que possibilitem subsídios para as práticas sociais, nas quais o sujeito possa utilizar seus saberes em situações do cotidiano quando necessário.

\section{Educação não formal enquanto prática libertadora}

Ao partir da compreensão de educação enquanto uma prática social libertadora que busca o desenvolvimento dos sujeitos nos diversos aspectos - crítico, cognitivo, político, afetivo e motor - é legítimo reafirmar que educar não é algo exclusivo do espaço escolar.

Para Freire (1987), educar consiste em formar sujeitos livres, com base em uma prática humanizada que verdadeiramente contribua para o processo de emancipação dos sujeitos. Logo, no contexto da educação não formal, o diálogo crítico e libertador deverá ser feito com as comunidades, na luta constante pela transformação do mundo enquanto um lugar justo de viver. Para tanto, é preciso refletir sobre esse processo libertador, por isso a educação precisa ser livre e reflexiva. E esse processo não acontece apenas nas escolas, afinal pode e deve existir nos espaços de militância e movimentos sociais.

Ainda segundo a lógica freiriana, é importante que cada sujeito, no processo de libertação, se reconheça como homem e mulher, ambos capazes de ser, existir e transformar o mundo. Assim a educação amparada na prática da liberdade é contrária à prática da dominação, e sugere a negação do homem abstrato, isolado, desligado do mundo, bem como nega esse mesmo mundo como uma realidade ausente dos homens (FREIRE, 1987).

Conforme aponta Freire (1981), a prática educativa (e enfatiza-se aqui, sobretudo, a educação não escolar) implica na concepção dos seres humanos no mundo e isso envolve desejo, trabalho, uma ação transformadora, que pode resultar no mundo transformado, através de homens e mulheres capazes de ter a percepção crítica da realidade. 


\section{-Revista de Iniciação à Docência, v.6, n.2, 2021- \\ Publicação: dezembro, 2021 - ISSN 2525-4332}

Nessa perspectiva crítica, é pertinente assegurar que, na educação não formal, o conhecimento enquanto veículo de libertação possibilita a transformação social e a formação de habilidade, diversas, socialização, construção de caráter cidadão, além de favorecer a atitude reflexiva frente às identidades culturais de cada um. É preciso então que o ato de educar tencione a renúncia frente aos movimentos de alienação, assumindo uma postura revolucionária e libertadora.

\section{Pegadas de areia nos caminhos metodológicos}

Optou-se pela pesquisa de natureza qualitativa e descritiva que, segundo Minayo (2009), permite uma maior interação entre os sujeitos (pesquisador e pesquisados); com caráter exploratório, dando possibilidade de uma busca mais detalhada para a comprovação do objeto pesquisado. De uma forma geral, as investigações qualitativas têm como ponto principal entender, descrever e, algumas vezes, explicar os fenômenos sociais e culturais de grupos sociais e/ou do indivíduo.

Tratou-se de um estudo de caso sobre a atuação do pedagogo na Associação Beneficente Oásis (nome que remete à presença de água e fertilidade em meio ao deserto), no bairro da Katiara, em Amargosa, Bahia, de modo que os pesquisadores tivessem contato direto com o fenômeno a ser estudado, a fim de obter informações sobre os sujeitos no próprio contexto. Para Bogdan e Biklen (1991), o estudo de caso é sempre um recorte, quando partimos da parte mais larga de um funil até encontrar seu cerne, seu foco de interesse, que pode ser um grupo, um contexto, uma única fonte documental, um evento ou ainda um acontecimento específico. Um estudo de caso jamais pretende reduzir um contexto amplo em suas partes constituintes, embora toda delimitação possa expor a pesquisa a certos riscos de distorções (FLICK, 2009; GIBBS, 2009; YIN, 2001). Por outro lado, é importante destacar que o caso estará sempre integrado ao todo, ou seja, ao cenário que ele compõe.

Utilizaram-se, para tanto, observações participantes na Associação e entrevista semiestruturada com a pedagoga que atua nesta organização da sociedade civil, tendo sido coordenadora de projetos entre 2014 e 2018. Esse modelo de diálogo revela-se flexível para fazer outras indagações que não estão no roteiro, diante daquilo em que o entrevistado revela ou informa, enriquecendo ainda a pesquisa.

Dessa forma, considera-se pertinente compreender a atuação própria do campo de pesquisa, que exige observar o comportamento do outro e sua rotina, estabelecendo relações com a teoria, "o pesquisador deve propor uma operação que facilita o desvendamento de sentidos implícitos aos acontecimentos do campo, nos termos dos próprios participantes" (MANTOVANI; BAIRRÃO, 2005, p. 42).

Para a análise dos dados, optou-se pelo diálogo com os autores que estudam a educação não formal e a perspectiva de Paulo Freire. Espera-se que os dados obtidos 
através da observação participante e do roteiro de entrevista possam auxiliar no entendimento dos fatores que influenciam na dinâmica da atuação do pedagogo nesses espaços. De acordo com Oliveira (1996), na observação participante:

[...] o pesquisador assume um papel perfeitamente digerível pela sociedade observada, a ponto de viabilizar uma aceitação senão ótima pelos membros daquela sociedade, pelo menos afável, de modo a não impedir a necessária interação (OLIVEIRA,1996, p. 21).

O pesquisador participante tem relação de parceria na sua atuação no campo pesquisado, havendo uma aproximação entre pesquisador-grupo-pesquisado, sendo necessária uma postura de diálogo entre eles. Para isso, Oliveira (1996) propõe que o que está em jogo na observação participante é a "intersubjetividade", que diz respeito a não somente observar o entorno e o outro, mas, sobretudo, inclui saberes locais, opiniões, pensamentos, sentimentos dos interlocutores com os quais se convive em imersão no processo da pesquisa.

\section{O olhar humano é quem concebe um Oásis}

A Associação Beneficente Oásis trabalha com crianças de 7 a 12 anos, totalizando 46 crianças regulares (assíduas) e 55 matriculadas no ano de 2019, participantes no seu contra turno escolar. São estudantes da Escola Municipal Dom Florêncio Sisínio Vieira, no próprio bairro da Katiara, em Amargosa, Ba.

Os grupos de adolescentes não continuam frequentando o Projeto, por conta do modelo escolar adotado a partir de 2019, na Escola Municipal Professora Dinorah Lemos da Silva, do bairro da Katiara, que oferece o ensino integral ocupando o tempo dos estudantes durante todo o dia.

As atividades do Projeto Social também envolvem as moradoras do bairro: está ativo o grupo de 24 mulheres, com idades entre 30 a 55 anos. Na sua maioria são as próprias mães das crianças que residem na comunidade, principalmente, as moradoras do bairro, donas de casa que convivem com a desigualdade social; com uma condição financeira desfavorável, que se encontram fora do mercado de trabalho. Essas pessoas estiveram presentes na instituição nos dias em que os pesquisadores estiveram em campo, realizando observações participantes.

A pedagoga entrevistada nesta pesquisa foi coordenadora do espaço e hoje ainda atua como colaboradora dos projetos. Ela tem uma rotina na organização, de modo que realiza as seguintes atividades: às terças pela manhã, no período matutino, faz visitas às casas das crianças que não comparecem às atividades, a partir de um acompanhamento longitudinal cuidadoso e um olhar de acolhimento às famílias; geralmente nos períodos vespertinos realiza também atividades pedagógicas ao lado das crianças nas salas do projeto. Nas quartas e sextas-feiras, especificamente pela manhã, desenvolve atividades de artesanato e a atividade temática do dia. Além disso, ela permanece os outros turnos 


\section{-Revista de Iniciação à Docência, v.6, n.2, 2021- \\ Publicação: dezembro, 2021 - ISSN 2525-4332}

na associação resolvendo casos internos, realizando planejamento pedagógico e administrativo e recebendo crianças, adolescentes e mulheres para eventuais diálogos e situações de acolhimento.

O papel do pedagogo, em um espaço de educação não formal, sem dúvida, envolve vínculos afetivos ou ainda, nas palavras de Freire (1996, p. 159), um "querer bem": "significa, de fato, que a afetividade não me assusta, que não tenho medo de expressá-la". Freire (1996) conversa conosco na Pedagogia da Autonomia, quando define os saberes necessários à prática educativa: no nosso caso, diríamos que atuar em educação não formal exige respeito aos saberes do outro, estética e ética, criticidade, corporeificação das palavras pelo exemplo, aceitação do novo, rejeição a qualquer forma de discriminação, reconhecimento da identidade cultural, respeito à autonomia, humildade, tolerância, luta por direitos, curiosidade, abertura, liberdade, generosidade, alegria, esperança e afeto, muito afeto.

A instituição Oásis surgiu com a necessidade de realizar, no bairro da Katiara (uma comunidade às margens do centro comercial da cidade), um trabalho com crianças, adolescentes e mulheres que se encontram com demandas diversas e vivem em um local com poucos recursos financeiros.

O fundador foi um missionário do Cristianismo chamado Jeremias, que é filho da cidade de Amargosa, Ba, sendo um projeto originado em Curitiba, no Paraná há 5 anos. A instituição não tem fins lucrativos, todos os serviços são gratuitos. Para sua sobrevivência e manutenção, buscam-se parcerias com voluntários, doadores, contribuintes de utensílios e materiais.

As instalações físicas contam com uma varanda, onde são realizadas algumas atividades da instituição, duas salas para atividades, uma sala de almoxarifados e uma cozinha; um banheiro e uma sala onde fica a secretaria. Em frente, nas salas em que são realizadas as atividades, encontram-se prateleiras, contendo materiais que são utilizados, para o uso na rotina, como caderno, lápis, lápis de cor, borracha, cola, tesoura, livros para estudos bíblicos, régua, canetas, pincel, entre outros.

O espaço é todo construído e estruturado para que os materiais estejam acessíveis às crianças, para que elas possam alcançar, manusear, utilizar livremente. Para Freire (1996, p. 66): “o respeito à autonomia e à dignidade de cada um é um imperativo ético e não um favor que podemos ou não conceder uns aos outros". Permitir que a infância se assenhore dos espaços é parte de um rigor metodológico e pedagógico.

O turno de funcionamento é sempre diurno (matutino e vespertino). Em 2018, o quadro de funcionários contava com quatro educadores e monitores no turno matutino e quatro no vespertino. No turno matutino eram trinta e uma pessoas inscritas e participando; no vespertino, cinquenta e cinco pessoas inscritas e frequentando. 


\section{-Revista de Iniciação à Docência, v.6, n.2, 2021- \\ Publicação: dezembro, 2021 - ISSN 2525-4332}

Há diversidade na área de atuação e situação funcional dos profissionais: existem voluntários e colaboradores nas áreas de educação, assistência social e psicologia comunitária. Os responsáveis da área pedagógica são: um coordenador, educadores, orientador e uma psicóloga. No administrativo, contam com uma secretaria e todos os voluntários, sem exceção, devem ser responsáveis pelo lanche e pela limpeza do ambiente.

No caso dos profissionais da educação, encontram-se diferentes formações na equipe: os monitores têm, pelo menos, a formação inicial do ensino fundamental; os educadores possuem magistério, pedagogia ou licenciatura. Existem, dentro da instituição, formação e capacitação, nas quais os educadores já participaram, como: formação continuada, "formação em educação por princípios" (método cunhado pelos próprios participantes do projeto Oásis) e em prática pedagógica. A pedagoga do Projeto, em entrevista a um dos pesquisadores, explica um pouco sobre como se dá essa educação por princípios: “a Educação por Princípios é uma abordagem educacional, uma maneira de ensinar e aprender que coloca a Palavra de Deus no coração".

$\mathrm{Na}$ comunidade da Katiara, as religiões cristãs parecem revelar uma forte influência nos cotidianos e na forma de pensar e agir. A organização não governamental Oásis foi fundada por um missionário cristão e não se apresenta como associação laica. Ao contrário, a equipe fundadora sempre deixa explícito que há uma atuação e uma formação atreladas ao cristianismo. Desse modo, é importante destacar que os pedagogos que atuam nesse espaço não formal não precisam ser cristãos, tampouco converter-se à religião nativa, porém devem ser respeitados e atuar respeitando a cultura local, seus valores, suas cosmovisões.

Assumir-se cristã é eticamente possível para uma organização da sociedade civil, desde que essa prática missionária não seja escamoteada por atuações melindrosas de conversão do outro sem seu consentimento, o que não parece ser o caso do Projeto Oásis. Quando a associação se assume claramente cristã (tanto em sua forma de trabalhar quanto em seus métodos pedagógicos) e isso fica explícito a todos os participantes, há nesse contexto transparência, respeito e liberdade. "A assunção de nós mesmos não significa a exclusão dos outros. É a 'outredade' do 'não eu', ou do tu, que me faz assumir a radicalidade do meu eu” (FREIRE, 1996, p. 46). Além disso, na prática educativa freiriana, você não precisa se transformar em outro, mas respeitá-lo, de modo que a questão do respeito à identidade cultural é ponto fundante (FREIRE, 1996).

A pedagoga do Oásis orienta como acontecem as reuniões com a equipe, mostrando que os princípios da instituição são abertamente discutidos e dialogados, com a intenção de oferecer igualmente um espaço de apoio aos voluntários nessa prática educativa:

[...] porque é importante trabalhar tanto na metodologia da educação por princípio pra eles, tá aprofundando mais, não que eles não conheçam, todos eles têm acesso à literatura, artigos, no momento que a gente faz o planejamento, 


\section{-Revista de Iniciação à Docência, v.6, n.2, 2021- Publicação: dezembro, 2021 - ISSN 2525-4332}

que acontece, sempre tem uma temática nova, a gente se reúne com o coordenador, então a gente conversa, tira dúvidas sobre a metodologia, o planejamento [...] a questão da rotina, de trabalhar (PEDAGOGA DO OÁSIS, ENTREVISTA, 2019).

O Oásis não deixa margens para dúvidas sobre sua perspectiva pedagógica, pois discute com clareza esse aspecto com seu grupo de voluntários, educadores, doadores e conviventes. Os grupos acontecem da mesma forma com as mulheres da comunidade, as responsáveis e cuidadoras de referência das crianças e adolescentes, já que, em sociedades ocidentais e capitalistas, o cuidado à infância é comumente ocupado por elas.

A instituição apresenta as seguintes áreas de atuação: artes, cultura, pedagogia e esportes. As atividades educacionais oferecidas são: literatura, inglês, artesanato, "devocional e temática", dança, música, recreação e oficinas. A pedagoga tenta explicar como funcionam:

As atividades acontecem dentro da proposta da faixa etária das crianças mesmo. Por exemplo o inglês e o espanhol eles trabalham muito de forma contextualizada. Trabalha a gramática, mas de forma mais lúdica, com música, poesia, com saudações... é uma língua no sentido de trabalhar a oralização, não a gramática da língua, entende? Então eles trabalham os princípios dentro das atividades deles identificando no conteúdo que ele tá trazendo. Por exemplo ele traz uma poesia falando sobre natureza para oralizar a criança na língua inglesa ou espanhol, então irá identificar o princípio naquela poesia.

Freire (1987) defende que a educação deve se distanciar do modelo bancário, em que o educador, suposto detentor do saber, deposita no educando (como uma tela em branco) todos os seus conhecimentos; ao contrário, a educação deve ser significativa para quem ensina (seja ele o docente ou discente) e para quem aprende (seja ele o professor ou o estudante). Estudar, portanto, deve se apresentar como uma estratégia rica em reinvenção, recriação e transformação, como forma de reler e reescrever o mundo (FREIRE, 1987).

O professor de artesanato ele trabalha muito com as artes plásticas: com pintura de tela, de muro, grafite. Isso o professor, a professora de arte, ela já tem outra pegada, ela trabalha manual, por exemplo sucatas transforma em brinquedos, dobradura, recortes, colagem. Literatura ela trabalha com contos, fábulas... né... ela faz sempre um registro que é uma arte, um reconto da história que ela fez, para a criança ter a oportunidade de expor também o que ela entendeu sobre a história trabalhada no dia (PEDAGOGA, ENTREVISTA, 2019).

Freire (2010) aponta a importância da afirmação do homem como sujeito, engajado na ação transformadora de sua realidade, senhor de sua cultura, de suas crenças e convicções, suas produções, sua voz, aquele que opta e decide. Assim são as crianças, em contato com as sucatas, produzindo seus próprios brinquedos, ao transformar, reutilizar e reciclar o real, o "lixo", transmutando o "rejeito" em arte, metamorfoses, revoluções, subversões. A infância que mergulha em diferentes expressões, que transita entre o imaginário, o simbólico e o real, vocifera suas palavras, esboça seus traços, traduz-se em grafites, telas e muros urbanos, assenhora-se de suas pinceladas, empodera-se em obra de arte. 
Na comunidade, além da Associação Oásis, que desenvolve trabalhos sociais, também há um grupo de "Resgate": projeto de cunho religioso, sendo destinado aos estudos bíblicos, ministrados por evangélicos da Igreja Assembleia de Deus de Ribeirão Preto, na Avenida São Cristóvão, no bairro da Katiara em Amargosa, com sua sede em Ribeirão Preto, São Paulo, voltado para dogmas religiosos, do qual já fez parte uma das autoras do presente manuscrito. O objetivo do Projeto Resgate é o respeito e a dedicação a quem precisa, foi criado há mais de 17 anos e atualmente acolhe e cuida de crianças, adolescente e jovens do bairro da Katiara (Amargosa, Ba).

\section{A escuta sobre a bruteza da vida quando se é nativo do deserto}

Uma das autoras deste presente estudo conhece bem a pedagoga entrevistada nesta pesquisa, a Associação Oásis e, sobretudo, o bairro que abriga essa organização, pois é moradora desta comunidade. Frequentou o projeto Resgate, desde o seu início em 2005, tendo formado um grupo de 15 adolescentes pioneiros no bairro, ao qual incluiu membros de sua própria família. As atividades eram ministradas por membros da Igreja Redenção, que também residem no bairro até hoje e permanecem com o mesmo projeto, possuindo destaque não só com as crianças e sim com a família e a comunidade.

No início do projeto, os encontros aconteciam aos domingos com a atividade religiosa devocional, aula de dança e coral, por meio de ensaios de coreografias e letras de canções/hinos gospel, apresentados sempre nas festas da igreja. Os adolescentes e jovens eram acolhidos na própria varanda da casa da família responsável pelo projeto.

A parte mais intensa e profunda desse encontro com o Oásis ocorreu especificamente em 2018 e 2019, através de visitas diárias e depois semanais na instituição, a partir de observações participantes e atuações em oficinas, sempre na presença da pedagoga entrevistada nesta pesquisa.

As oficinas versam sobre temas variados, tais como o ensino e a aprendizagem da língua inglesa e do espanhol, através de uma metodologia lúdica com a utilização de músicas, poesias, saudações, expressões e vivências do cotidiano. Ocorrem também oficinas de artesanato e artes plásticas, com pintura de tela, de muro, grafite, reciclagem, construção de brinquedos a partir de sucatas, confecção de origamis e dobraduras, recortes, colagens. Não se pode deixar de citar as atividades de Literatura, que envolvem contação de histórias, nas quais as crianças entram em contato com diversos gêneros literários e têm a oportunidade de recontar de sua própria maneira. De fato, as modalidades das oficinas são múltiplas e variadas: música, dança, jogos, informática.

Uma das autoras deste estudo esteve presente em inúmeras dessas oficinas que contavam com a participação de algum educador voluntário e das crianças e adolescentes conviventes na Associação. Freire (2021) menciona a importância de uma educação transformadora, desenvolvedora de consciências críticas, baseada em múltiplas 


\section{-Revista de Iniciação à Docência, v.6, n.2, 2021- \\ Publicação: dezembro, 2021 - ISSN 2525-4332}

experiências e existências, estimulante de criatividades diversas e do pensar autêntico, "que não se deixa emaranhar pelas visões parciais da realidade, buscando sempre os nexos que prendem um ponto a outro, ou um problema a outro" (FREIRE, 2021, p. 84).

Ao longo desse período até os dias de hoje, muita coisa se modificou, os atores, o cenário, a cena, a ação; o projeto mudou de sede, o mundo mergulhou na maior tragédia humanitária e sanitária das últimas gerações, o Brasil está imerso em uma crise política, de saúde pública, educacional, social, econômica, sem precedentes. A pesquisa de campo não está em andamento, mas as organizações populares não pararam, os espaços de educação não formal e suas comunidades seguem firmes, tentando sobreviver e (re)existir a uma pandemia.

Quanto à autora que vive nesta comunidade descrita no presente artigo, ela graduou-se em Pedagogia e mantém-se nativa no mesmo meio em que desenvolveu esta investigação científica, possibilidade largamente estudada por autores da antropologia, a exemplo de Silva (2006), e da etnopsicologia, a exemplo de Bairrão (2005) e sua concepção de escuta participante. Ela é habitante e residente na Katiara desde a infância, conhece com intimidade seus anseios, angústias e louros, muito antes de sua entrada na universidade. Mesmo com o estigma social de comunidade com o maior índice de violência e mortes na cidade de Amargosa, a pesquisadora em referência preserva a admiração e a orgulhosa assunção de sua identidade cultural associada à Katiara, onde habita há quase 30 anos. Nesse sentido, o campo é e continuará sendo "vivo", apesar, à revelia e independentemente de nossas "escrituras acadêmicas".

\section{Considerações finais}

Através dos dados de investigação desta pesquisa, é possível afirmar que a modalidade da educação não formal assume dimensões importantes na sociedade atual. Neste cenário, constroem-se relações de trabalho de pedagogos em espaços não convencionais que necessitam das práticas pedagógicas, rompendo com o fundamento de que a formação do educador é restritamente direcionada para o contexto da escola.

Com base nas discussões levantadas por este estudo, percebeu-se que o pedagogo, nos espaços de ONG's, Associações, Movimentos Populares e Projetos Sociais, apresenta, em seu ofício, flexibilidade e fluidez. Antes de propor, impor ou estabelecer nortes, projetos e estratégias baseadas em suas teorias, ele, acima de tudo, busca tecer uma escuta da comunidade, acompanha as crianças, os adolescentes e suas famílias: o que eles desejam; do que eles precisam; quais são suas demandas? A partir do refinamento desta escuta sensível ao outro, ele poderá negociar suas habilidades, encaixar suas aptidões, aplicar suas teorias, aprimorar sua prática, revelando, assim, versatilidade, humanidade e criatividade de sua profissão.

Em conformidade com a pedagogia de Freire, a ação pedagógica, na educação não 
formal, revela-se em ato, em cada olhar, em cada fala, em uma reflexão, no acolhimento, respeito às crenças, saberes e religiosidades da comunidade que a recebeu. É por meio desse tecido de atuação que percebemos como o pedagogo atua neste cenário dos espaços não escolares cuja proposta é formar sujeitos críticos a partir da educação popular e libertadora voltada à autonomia do sujeito, à luta pela justiça e capaz de transformar mundos.

Não, transformar não é fácil. Muito menos fácil é transformar-se. Crescer, adolescer, envelhecer, amadurecer, formar-se, metamorfosear-se, gestar, parir, (re)nascer, (re)existir, resistir... transmutar a si mesmo é como trilhar terras arenosas, caminhos de deserto. Revolucionar o outro e o mundo é cenário ainda mais "arestoso e amargo" (toma-se aqui de empréstimo as palavras de Freire em Pedagogia da Autonomia). Sempre se tem a vontade de perguntar às cobras se trocar a pele dói. Suponha-se que sim. Não deve ser menos doloroso confinar-se em um casulo para só depois alçar voo. Mas se não o fizer, elas não crescem e não se libertam. É assim que seguem as asas da educação, porque ela é espiralada e dialógica. Os rios não fluem em linha reta. Ziguezagueiam por muitas montanhas e vales, secam e retomam o curso, ainda que nas agruras desérticas do sertão. Mas é no fim dos caminhos que renascem oceano, como num Oásis.

\section{Referências}

BRANDÃO, Carlos Rodrigues. O Que é Educação. São Paulo: Brasiliense, 2007.

BAIRRÃO, José Francisco Miguel Henriques. Escuta Participante como Procedimento de Pesquisa do Sagrado Enunciante. Estudos de Psicologia, v. 10, n. 3, p. 441-446, 2005.

FREIRE, Paulo. Extensão e Invasão Cultural. In: Souza. A. I. (Orgs.). Paulo Freire: vida e obra. São Paulo: Expressão Popular, 2010, p. 261-282.

FREIRE, Paulo. Pedagogia da Autonomia: saberes necessários à prática educativa. Rio de Janeiro: Paz e Terra, 1996.

FREIRE, Paulo. Pedagogia do Oprimido.17 ed, Rio de Janeiro, Paz e Terra, 1987.

FREIRE, Paulo. Pedagogia do Oprimido. Rio de Janeiro, Paz e Terra, 2021.

FREIRE, Paulo. Ação cultural para a liberdade. $5^{\text {a }}$ ed., Rio de Janeiro, Paz e Terra, 1981.

GOHN, Maria da Gloria. Educação Não Formal e o Educador Social: atuação no desenvolvimento de projetos sociais. São Paulo: Cortez, 2010.

GOHN, Maria da Gloria. Educação Não Formal e Cultura Política: impactos sobre o associativismo do terceiro setor. São Paulo: Cortez, 1999.

LIBÂNEO, José Carlos. Pedagogia e Pedagogos, para quê? São Paulo: Cortez, 1998.

MANTOVANI, A.; BAIRRÃO, J. F. M. H. Psicanálise e religião: pensando os estudos afrobrasileiros com Ernesto La Porta. Memorandum Memória e História em Psicologia, v. 9, p. 42-56, 2005.

MINAYO, Maria Cecília de Souza (Org.). Pesquisa Social: teoria, método e criatividade. 
Petrópolis, RJ: Vozes, 2009.

OLIVEIRA, Roberto Cardoso de. O Trabalho do Antropólogo: olhar, ouvir, escrever. Revista de Antropologia. v. 39, n 1, p. 13 - 37, 1996.

SCHNORR, Giselle Moura. Pedagogia do Oprimido. In: Souza. A. I. (Orgs.). Paulo Freire: vida e obra. São Paulo: Expressão Popular, 2010, p. 67-96.

SILVA, V. G. $O$ antropólogo e sua magia. São Paulo: Edusp, 2006.

TRILLA, Jaume. A Educação Não Formal. In: ARANTES, Valéria Amorim (Org.). Educação Formal e Não Formal: pontos e contrapontos. São Paulo: Summus, 2008. 